\title{
Alice em São Paulo: Atravessamentos do Corpo na Metrópole Inacabada
}

\author{
João Vitor Resende Leal \\ Pós-doutorando com bolsa Fapesp \\ do Programa de Pós-Graduação em \\ Multimeios do Instituto de Artes da \\ Universidade Estadual de Campinas \\ (PPGMM-IA-Unicamp). \\ E-mail: jv.leal@gmail.com.
}

Resumo: O artigo busca examinar alguns dos princípios que regem a representação da metrópole contemporânea na produção audiovisual brasileira. Para além do progresso e do dinamismo típicos da cidade moderna, o discurso contemporâneo aborda a metrópole como espaço de desorientação, que catalisa e amplifica experiências sensoriais. Investigaremos em particular a representação de São Paulo na série televisiva Alice (2008), na qual a protagonista tem a vida afetiva atravessada por suas descobertas da cidade, numa "estratégia feminina de leitura do espaço" (Bruno, 2007). Destacando outras produções paulistanas da primeira década dos anos 2000 , refletiremos ainda sobre as estratégias de abordagem do espaço urbano no cinema contemporâneo, questionando a tendência de "retorno ao real" através da sensorialidade.

Palavras-chave: São Paulo, espaço urbano, cinema, realismo, Alice.

\section{Alice en São Paulo: Cruces del Cuerpo en la Metrópoli Inacabada}

Resumen: Este artículo pretende analizar algunos de los principios de la representación de la metrópoli contemporánea en la producción audiovisual brasileña. Además del típico progreso y dinamismo de la ciudad moderna, el discurso contemporáneo aborda la metrópoli como un espacio de desorientación, que cataliza y amplifica las experiencias sensoriales. Para esto, se centra, más específicamente, en la representación de São Paulo en la serie de televisión Alice (2008), en la cual la protagonista tiene su vida emocional con sus descubrimientos de la ciudad, en una "estrategia de lectura del espacio femenino" (Bruno, 2007). Se destaca otras producciones de la cuidad de la primera década del 2000 para reflexionar sobre las estrategias de abordaje del espacio urbano en el cine contemporáneo, cuestionando mediante la sensorialidad la tendencia de la "vuelta a lo real".

Palabras clave: São Paulo, espacio urbano, cine, realismo, Alice.

\section{Alice in São Paulo: The Entangled Body in the Unfinished Metropolis}

Abstract: This paper seeks to examine some of the principles governing the representation of the contemporary metropolis in Brazilian audiovisual media. Beyond the progress and dynamism inherent to the modern city, contemporary discourse addresses the metropolis as a disorienting space that catalyzes and amplifies sensory experiences. Thus, we will investigate the representation of São Paulo in the television series Alice (2008), whose protagonist's life is pierced with her impressions of the city as she engages in a "feminist strategy of reading space" (Bruno, 2007). Based on other audiovisual representations of the city from the first decade of the 2000s, we also intend to discuss the strategies employed by the contemporary world cinema for addressing the urban space, questioning its tendency to use sensory appeals towards the "return of the real".

Keywords: São Paulo, urban space, cinema, realism, Alice. 
Dentre as muitas "cidades invisíveis" imaginadas pelo escritor Italo Calvino (1990), Tecla se destaca por oferecer uma paisagem dominada por guindastes e armaduras metálicas, parcialmente ocultos por tapumes e defesas de pano. Os habitantes de Tecla não se ocupam de outra coisa senão de sua perpétua construção:

À pergunta: Por que a construção de Tecla prolonga-se por tanto tempo?, os habitantes, sem deixar de içar baldes, de baixar cabos de ferro, de mover longos pincéis para cima e para baixo, respondem:

- Para que não comece a destruição. - E, questionados se temem que após a retirada dos andaimes a cidade comece a desmoronar e a despedaçar-se, acrescentam rapidamente, sussurrando: - Não só a cidade. (Calvino, 1990, p.117)

Cidade não planejada e de crescimento desordenado e infinito, povoada por uma massa de trabalhadores cuja única função é construí-la, Tecla oferece uma síntese da metrópole contemporânea. Ela se distingue da típica metrópole moderna aquela que tem como modelo a Paris da multidão, dos veículos e do flâneur, exaltada pela poesia de Baudelaire e pelo ensaio de Benjamin que a projeta como "capital do século XIX" (Benjamin, 1991). De fato, Tecla se dá menos ao olhar descompromissado e admirador do flâneur do que ao olhar exausto e desinteressado do trabalhador anônimo. Sua paisagem é menos definida por construções imponentes de funcionalidade e beleza do que pelos canteiros de obras. É uma metrópole que nunca está pronta, e interromper sua construção equivaleria a iniciar sua destruição.

A identidade de Tecla, como a de toda metrópole contemporânea, não pode ser definida em termos de uma estabilidade ou de uma utopia possível. Ao contrário, essa identidade só poderá estar (caso ousemos mesmo afirmar sua existência) em uma tentativa de definição já desiludida de qualquer possibilidade de alcance. Como sugere o antropólogo Marc Augé, "O paradoxo do mundo atual é que o desenvolvimento da cidade parece fazê-la desaparecer: nós temos o sentimento de ter perdido a cidade, mesmo que aí não exista nada mais senão ela" (2010, p. 91). Assim, na grandeza das distâncias, no vai e vem dos corpos, na proliferação das máquinas e das imagens e na mutação dos espaços urbanos (paisagem, arquitetura), o habitante de Tecla, ou então seu visitante ocasional, se perde na cidade e perde a cidade.

Escrito em 1972, As Cidades Invisíveis traz uma ideia que foi posteriormente revisitada por diversos autores: superado o fascínio da modernidade e as utopias que associam o progresso industrial e urbano ao bem-estar social e à realização individual, a metrópole se revela uma miragem, como o oásis sempre mais adiante em meio às dunas móveis do deserto. Para Augé, a metrópole contemporânea "como utopia realizada, não existe em parte alguma", sendo antes uma ilusão cujos termos básicos - transparência, luz e circulação - apenas aludem àquilo que ela nunca será (2010, p. 93). Sua identidade, como diria Zygmunt Bauman (2001), mais do que frágil, é líquida, ou seja, não possui forma definida, mas sim uma natureza fluida, como das coisas que transbordam ou escorrem por entre os dedos.

${ }^{1} \mathrm{O}$ nome Tecla pode ser retraçado a Santa Tecla, primeira mulher mártir do século I, convertida ao cristianismo pelo apóstolo Paulo de Tarso, conhecido hoje como São Paulo.

\footnotetext{
${ }^{2}$ A padronagem foi desenvolvida pela arquiteta Mirthes dos Santos Pinto e adotada pela prefeitura de São Paulo após um concurso municipal realizado em 1965 (TV Folha, 2015).
}

Não é difícil convocar São Paulo como cidade real, capaz de traduzir a Tecla imaginada por Calvino. Para além do parentesco etimológico ${ }^{1}$, veremos que a capital paulista se aproxima da fictícia Tecla por ser frequentemente descrita como uma cidade de múltiplas identidades (ou, por isso mesmo, de identidade fragmentada), uma "selva de pedras" ou um "mar de prédios" a perder de vista no horizonte. O balanço das árvores nessa "selva" ou das ondas nesse "mar" se expressaria nas variações de luzes, na intensidade do trânsito, nas transformações urbanísticas e arquitetônicas. A nosso ver, até a padronagem clássica das calçadas - cuja forma geométrica evoca um mapa estilizado do estado de São Pauloº - sugere, com seus encaixes angulosos, uma repetição sem fim (Figura 1). 


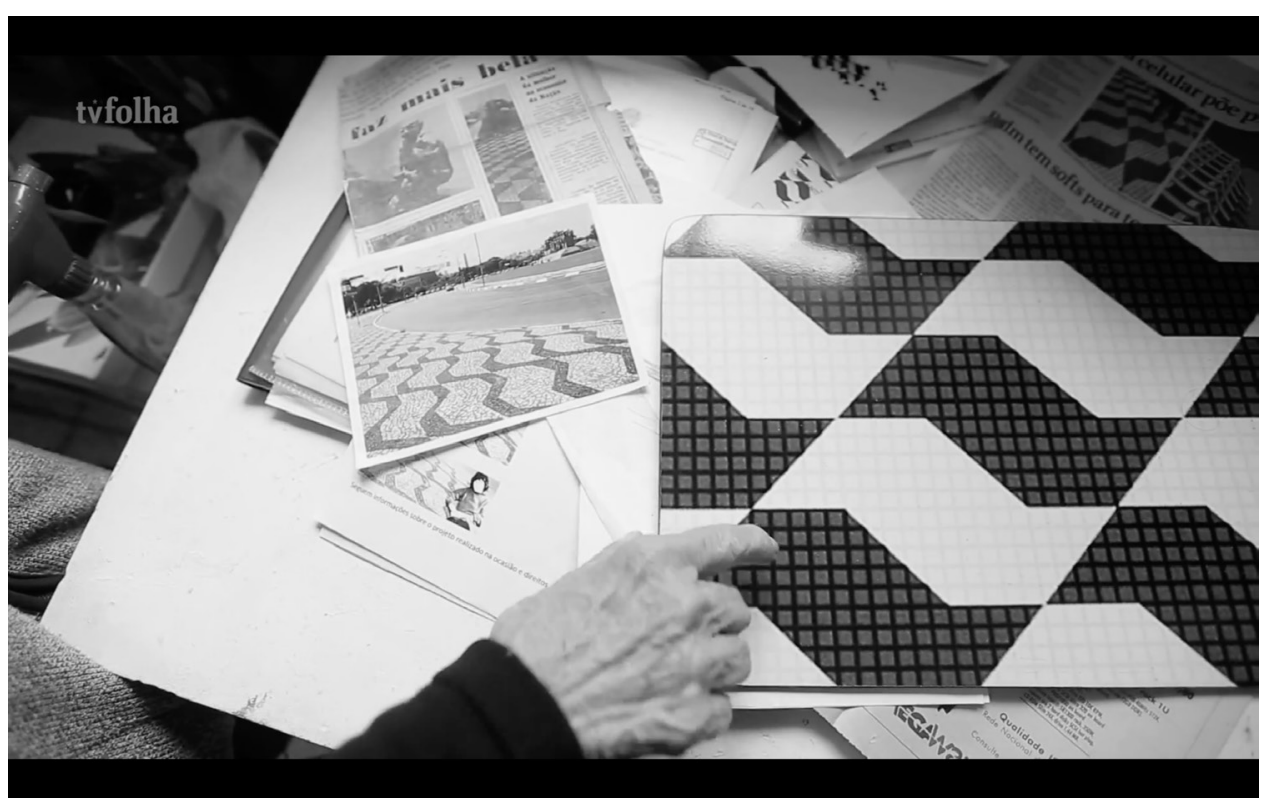

Figura 1: Padronagem clássica das calçadas paulistanas

Nota: Folha de S.Paulo, 2015

Em sua análise das representações visuais de São Paulo, Rubens Machado Jr. aponta uma "pobreza iconográfica" decorrente da ausência de referências perenes e estáveis - não há na cidade uma Torre Eiffel, um Corcovado, uma Estátua da Liberdade (Machado Jr., 2008, pp. 192-193). O pesquisador comenta a inconstância dos cartões postais da capital paulista, observando a grande variedade de lugares eleitos para representar a cidade: "Mais do que qualquer grande metrópole do século, em São Paulo não será muito fácil encontrarmos traços comuns entre os cartões postais mais vendidos de cada década" (Machado Jr., 2007, p. 118). Assim como Tecla, em perpétua construção, São Paulo não nos daria uma imagem visual acabada e plena de si mesma.

Tal imaginário da metrópole é reafirmado naquela que é, muito provavelmente, a representação mais disseminada da cidade na cultura popular - a canção "Sampa", composta por Caetano Veloso em 1978. Fazendo do cruzamento de duas avenidas centrais (Av. Ipiranga e Av. São João) sua paisagem central, a canção descreve uma experiência de desorientação ("é que quando eu cheguei por aqui eu nada entendi") em um espaço atravessado por forças incessantes ("a força da grana que ergue e destrói coisas belas"). Talvez diante da falta de outros predicados capazes de sintetizá-la, a cidade é classificada como "o avesso do avesso do avesso do avesso".

Neste artigo, partimos dessas reflexões iniciais sobre São Paulo para observar os princípios que regem a representação típica da metrópole contemporânea. Diferente das errâncias do flâneur moderno e para além dos signos habituais da modernidade urbana e industrial - a "cidade-máquina" do trabalho e da vontade de progresso (Xavier, 2006) -, veremos que os discursos acerca da São Paulo contemporânea priorizam estratégias fundamentalmente afetivas de leitura do espaço urbano, conjugando transparência, luz e circulação a experiências subjetivas de desorientação. Nesse trajeto, analisaremos como princípios associados à identidade da metrópole em geral, e de São Paulo em particular, têm sido expressos em termos narrativos e estéticos no meio audiovisual, mantendo-nos atentos a eventuais rachaduras ou emendas que possam surgir nessas representações. Através da análise da série televisiva Alice (2008), esperamos revelar como esse espaço, descrito em termos de fluxos ininterruptos e intensas transformações, catalisa e amplifica estímulos sensoriais, de modo a alimentar o imaginário que faz da metrópole um sedutor "país das maravilhas" (Carroll, 2010) - espaço não apenas destinado ao trabalho-progresso ou ao trabalho-alienação, mas também lugar de um encantamento voraz. Ao longo do texto, consideraremos ainda alguns filmes paulistanos da primeira década dos anos 2000, a fim de compreender melhor em que medida suas representações audiovisuais da cidade dialogam com certa tendência de "retorno ao real" que marca o cinema contemporâneo. 


\section{O Avesso do Avesso}

Está claro que a carência ou inconstância iconográfica é algo que, em algum grau, suscita ou legitima o discurso que exalta o dinamismo da metrópole. Nesse sentido, tecendo reflexões à luz de Benjamin, a antropóloga Paula Montero (2008) sugere que, em São Paulo, "Tudo flui, tudo é pressa, tudo é rapidez. A materialidade da cidade se perde na cinética do movimento" (p. 195); assim, continua ela, a "experiência cotidiana do urbano enquanto fluxo é a epítome da metrópole" (p. 192). A nosso ver, a imagem do "fluxo" evocada por Montero retoma a trinca transparêncialuz-circulação de Augé e se revela capaz de encapsular os elementos básicos da identidade metropolitana, tornando-a relativamente consistente - ou, talvez, assumindo melhor sua inconsistência. Nesse sentido, o "fluxo" não deixa de ser uma miragem destinada a dissimular o fato de que não haveria identidade alguma passível de descrição. É, pois, de sua indescritibilidade que a metrópole contemporânea parece extrair sua identidade:

A identidade de São Paulo está muito mais ancorada nas imagens criadas a respeito dela do que verdadeiramente no que ela é: múltipla, fragmentada e, portanto, pouco reconhecível e apreensível. A narrativa histórica associou seus acontecimentos mais significativos à velocidade, mobilidade, trabalho e progresso, palavras acessíveis e de simples compreensão, de grande impacto, quase como um slogan publicitário, que criam na "terra da garoa" uma bruma, uma neblina que envolve a memória do paulistano, induzindo-o a tomar essas palavras como elementos essenciais da identidade de São Paulo. (Leonarde, 2014, p. 209)

Assumindo o papel de definir o que é a metrópole ou servindo como uma cortina de fumaça que nos impede de ver que ela é indefinível, a imagem do "fluxo" ecoa no imaginário popular e, também, nas representações audiovisuais. Alguns filmes recentes, além de explorar a visualidade de São Paulo, parecem interessados em fazer da cidade um objeto de reflexão - continuando a tradição iniciada pelo documentário São Paulo, a Sinfonia da Metrópole (Adalberto Kemeny e Rodolpho Lustig, 1929) e revigorada, à época do Cinema Novo, por São Paulo S/A (Luís Sérgio Person, 1965). Filmes como Jogo Subterrâneo (Roberto Gervitz, 2005), Os 12 Trabalhos (Ricardo Elias, 2006), Não por Acaso (Philippe Barcinski, 2007), A Via Láctea (Lina Chamie, 2007), A Casa de Alice (Chico Teixeira, 2007) e Linha de Passe (Walter Salles e Daniela Thomas, 2008) tomam São Paulo não como "tema", "assunto" ou "cenário", mas como "um organismo vivo", "uma instância fundamental de mediação da vida social" (Feldman, 2008).

É nesse contexto que se situa a série Alice, produzida pela HBO Latin America com recursos da Ancine e direção geral dos cineastas Karim Aïnouz e Sérgio Machado. Alice teve uma única temporada (13 episódios), exibida entre setembro e dezembro de 2008, e foi concluída com dois telefilmes em novembro de 2010. Como veremos a seguir, ao longo da série, a urbanidade de São Paulo instiga e responde às inquietações da protagonista que por ela perambula. Mais do que oferecer representações realistas da cidade, a série filtra a realidade urbana nas experiências afetivas de Alice, propondo uma cartografia afetiva que evoca a Carte du pays de Tendre de que nos fala Giuliana Bruno ${ }^{3}$. Dessa forma, nossa discussão não irá se preocupar em fazer distinções entre a cidade real e sua representação. Ao contrário, optamos por assumir, sem buscar superar, o risco de confundir a cidade real com uma cidade imaginada, tendo aprendido com Calvino (1990, p.59) que há uma relação entre elas e, com Machado Jr. (1989, p. 1), que "as cidades que vemos no cinema transformam as cidades em que vivemos".

\section{Pela Toca do Coelho}

Alice (interpretada por Andréia Horta) é uma jovem de Palmas, Tocantins, que tem sua vida planejada em torno da família, do trabalho como guia de turismo e do casamento previsto para dali a um mês. Ela e o noivo já compraram o apartamento onde irão morar e escolheram nomes para os futuros filhos. Tudo isso é estabelecido no prólogo de "Pela Toca do Coelho", primeiro episódio da série, através de uma montagem com farto uso de fotografias. À inércia dessa vida planejada (e das imagens estáticas), será oposta uma viagem: ao receber a notícia da morte do pai, 
${ }^{4}$ Vale notar também os efeitos neon dos créditos de abertura, que remetem ao pós-modernismo do "neon-realismo" movimento paulistano dos anos 1980 marcado por filmagens em estúdio que proporcionavam representações deliberadamente artificiais da cidade. Sobre o "neon-realismo", ver Pucci (2008). de quem não tem notícia há anos, Alice decide ir a São Paulo para comparecer ao enterro e tratar da herança com a madrasta - herança que a colocará em posse de um galpão abandonado no bairro da Barra Funda. Ao final da série, ela ainda não terá retornado a Palmas. Na sequência dos episódios, que narram as aventuras de Alice na cidade, ela fará novos amigos e viverá novos romances, redescobrindo, por fim, através da revitalização do galpão herdado e com a ajuda da meia-irmã dez anos mais jovem, a verdadeira identidade do pai.

É interessante observar que a série mobiliza inicialmente uma estrutura narrativa similar àquela identificada por Cecília Mello no artigo "Um conto de duas cidades" (2013). Assim como os filmes analisados por Mello - Terra Estrangeira (Walter Salles e Daniela Thomas, 1995), Contra a Parede (Fatih Akin, 2004), Import/Export (Ulrich Seidl, 2007) e Que Horas são aí? (Tsai Mingliang, 2001) -, Alice nos apresenta, logo de entrada, uma nítida oposição entre imobilidade (stasis) e movimento, num encontro entre duas geografias que suscita "questões relacionadas ao tempo, ao espaço e à fabricação da memória" (Mello, 2013, p. 120). No lado da imobilidade está Palmas, cidade planejada que é vivida por Alice, de vida igualmente planejada, como signo de adequação e acomodação guia de turismo, Alice "domina" a cidade. Já ao lado do movimento, no oposto de Palmas, está a capital paulista, cujas primeiras imagens nos são dadas pela vinheta de abertura da série (Figuras 2-5): uma montagem dinâmica em espelhamentos e efeitos caleidoscópicos, que alterna imagens em timelapse do trânsito paulistano a close-ups do corpo da personagem. Sem surpresas, a vinheta termina com planos gerais de um "mar de prédios" 4 . Em entrevistas, o diretor Karim Aïnouz explica que, para a protagonista, a adequação equivaleria à morte (Feldman \& Eduardo, 2007,p. 14), e que São Paulo, "teia infinita de possibilidades", é usada na série "como imagem e espelho da personagem" (Mello, 2007). Ao decidir não retornar a Palmas, a personagem deixaria claro seu desejo de permanecer em movimento, em construção.
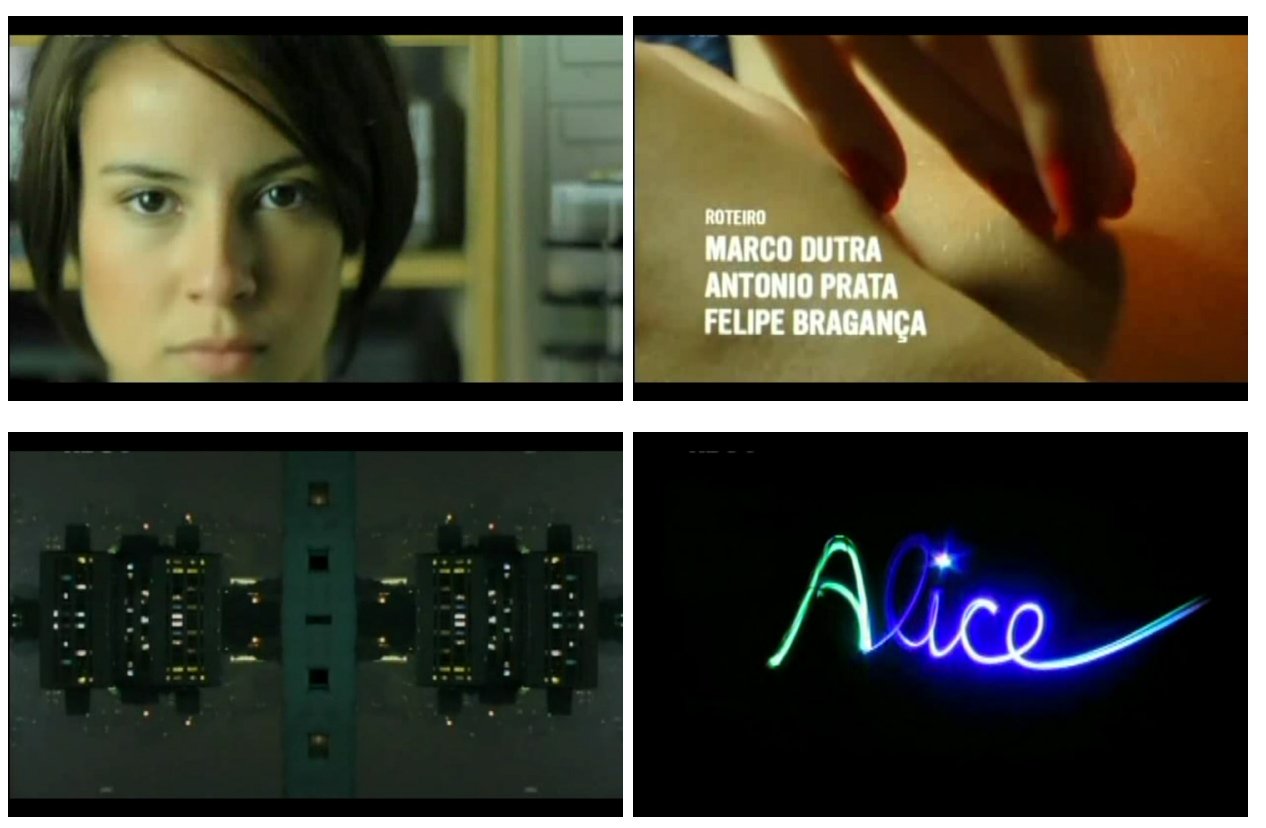

Figuras 2-5: Frames da vinheta de abertura

Nota: Alice, $\mathrm{HBO}, 2008$

Se a vinheta propõe um entrelaçamento conceitual e visual do corpo de Alice à topografia e à paisagem de São Paulo, é porque seus deslocamentos pela cidade se darão como uma jornada de autoconhecimento - jornada que visa uma elaboração da memória (do pai) e uma reativação dos desejos do corpo, ponto de contato basilar com o mundo ${ }^{5}$. Alice fica emaranhada à cidade: ao final do primeiro episódio, após perder o voo que a levaria de volta a Palmas, ela desce do táxi em meio ao trânsito e submerge no fim de tarde paulistano. Sua jornada não se dá meramente pela superfície das ruas, mas na espessura da cidade que ela mesma produz para si enquanto caminha.

\footnotetext{
${ }^{5}$ Não custa lembrar, com a fenomenologia, que estamos corporalmente entrelaçados à "carne do mundo": "a minha própria carne é um dos sensíveis no qual se faz uma inscrição de todos os outros, o sensível pivô do qual participam todos os demais, sensível-chave, sensível dimensional" (Merleau-Ponty, 2003, p. 234).
} 
${ }^{6}$ Numa passagem curiosa, Vivian Sobchack argumenta que, nas sociedades ocidentais, a prerrogativa de postular e organizar o espaço é tida como masculina, com as mulheres frequentemente confrontadas por "olhares que as situam e as convidam a existir apenas como corpos posicionados de modo imanente no espaço". A diferença na forma de vivenciar o espaço faria da desorientação um "problema hermenêutico" ameaçador para a identidade masculina, mas, "para as mulheres, pedir orientação é uma atividade mais familiar, mundana e reconfortante, que não provoca crise existencial alguma" (Sobchack, 2004, pp.29-35).
Já nessas primeiras experiências de Alice, São Paulo se mostra uma cidade de faróis e buzinas impacientes, transeuntes apressados em todas as direções, vendedores ambulantes. A experiência subjetiva da personagem orienta tal descrição do espaço, cumprindo a máxima segundo a qual não existe espaço neutro-como afirma a geógrafa Doreen Massey (2008, p. 30), "O espaço não existe antes de identidades/entidades e suas relações". Com desfoques e rápidas correções de enquadramento, planos fechados que abstraem as relações espaciais, quebras de eixo, descontinuidades e sobreposições das camadas sonoras, o espectador é feito, com Alice e assim como ela, de "passageiro que atravessa um terreno háptico e emotivo" (Bruno, 2007, p. 16). A experiência de estar perdido potencializa os estímulos sensoriais produzidos pela metrópole e, com isso, evidencia o espaço como produto de nossa própria percepção. Estar perdido é, pois, não conseguir situar o próprio corpo no espaço - uma experiência distante das "excursões prazerosas e sem rumo do flâneur que, por não ter destino definido, sempre chega onde quer" (Sobchack, 2004, p. 15). Em sua representação de São Paulo, Alice enfatiza o espaço como algo a ser construído pela/na experiência afetiva individual, um meio físico (site) muito além da vista que oferece (sight). Fazendo da personagem uma espécie de espectador "por procuração" da própria cidade, a série suscita uma postura espectatorial mais próxima à do viajante (voyageur) que do mero observador (voyeur). Essas passagens do sight ao site e do voyeur ao voyageur convocam o háptico numa "estratégia feminina de leitura do espaço" (Bruno, 2007, p. 16) ${ }^{6}$.

Outra maneira de atentar para a centralidade da relação entre corpo e cidade em Alice é evocando a recorrência de elementos da vida noturna em seu enredo. Boa parte das experiências da personagem se dão em ambientes marcados pela dança, consumo de drogas e sexo. A música eletrônica reforça a vocação contemporânea e global da metrópole, ao mesmo tempo que traz à tona sua sensualidade. Em sua primeira noite sozinha em São Paulo, Alice acaba em uma festa e se deixa levar para casa pelo DJ. A sequência termina ao amanhecer, com a montagem alternando imagens do noivo de Alice em seu carro na arborizada Palmas e da própria Alice caminhando pela Avenida Paulista até chegar ao Edifício Copan, onde sua tia administra um brechó. No percurso, ouvimos seu pensamento em voz over: "É esquisito, porque eu devia estar me sentindo mal, culpada. E o pior é que eu não estou." Em São Paulo, sobretudo pela vida noturna e pelo sexo, ela encontra meios de empregar seu corpo para se divertir e se redescobrir sem constrangimentos. A dinâmica da vida noturna é central na cidade que a série discursivamente constrói, permitindo-nos reconhecer a sensualidade que há no "fluxo": a metrópole contemporânea também é atravessada pelo prazer.

Mais adiante, nos episódios 7 ("Wonderland") e 8 ("A Guerra de Alice"), a vida noturna será novamente relacionada à construção identitária, agora nos termos de uma reconfiguração da memória do pai. Tendo revitalizado o galpão da Barra Funda, Alice o inaugura com uma festa e uma apresentação de Telecatch - modalidade de luta-livre da qual seu pai participava. A inauguração é um sucesso, apesar da greve que paralisa a cidade (pretexto para imagens do trânsito caótico) e da localização do galpão (comenta-se, em determinado momento, que uma antiga casa noturna do bairro será convertida em igreja evangélica). Dessa forma, Alice transforma o galpão numa fonte de renda segura que a permite se estabelecer em definitivo na cidade. Além disso, os preparativos para a inauguração a aproximam da meiairmã e a colocam em contato com antigos amigos do pai, que a ajudam a substituir a imagem do homem deprimido que a abandonou e cometeu suicídio pela imagem do homem que viveu intensamente suas paixões sem nunca realmente esquecê-la. Como uma ruína desenterrada da areia, o galpão deixa de ser um local abandonado para se tornar o deflagrador de lembranças e afetos. É na vivência do espaço - e não exatamente no tempo, como tanto se diz - que Alice revive e repara seu passado.

Ao longo da série e assim como a cidade, portanto, a personagem nunca nos dá uma imagem acabada e plena de si mesma. Para ambas, cidade e personagem, a questão é manter uma identidade coesa num contexto de incessantes transformações que torna impossível, justamente, o estabelecimento e a coesão de qualquer identidade.

Noutra sequência (episódio 9, "Em Busca do Ouro") que permite compreender melhor essas transformações, uma nova amiga de Alice, prestes a se mudar para outro 
${ }^{7}$ A Ponte Octávio Frias de Oliveira, na região sudoeste da cidade, foi inaugurada em maio de 2008. país, é levada num passeio de despedida para observar São Paulo "de um jeito que você nunca viu". Ela é conduzida ao alto da ponte estaiada (Figuras 6-7), que é hoje um cartão postal da cidade, mas que estava, à época das filmagens, ainda em construção ${ }^{7}$. A série parece sugerir que não há lugar melhor para contemplar a metrópole do que uma ponte (local de passagem por excelência), ademais inacabada, em obras, como as pontes de Tecla. No mesmo sentido, extrapolando o universo diegético, vale notar ainda o uso particular de ferramentas de geolocalização na campanha de divulgação da série: entre 2008 e 2010, a suposta localização da Alice ficcional era publicada na rede social Foursquare (Mascarenhas, 2014), convidando o espectadorusuário a acompanhar a protagonista até uma eventual segunda temporada (que não foi produzida). Nessa estratégia, os corpos de Alice e da cidade se encontram novamente entrelaçados, não apenas com a cidade real mobilizada pelo universo da ficção, mas, também, com a personagem ficcional aderindo à cidade real.
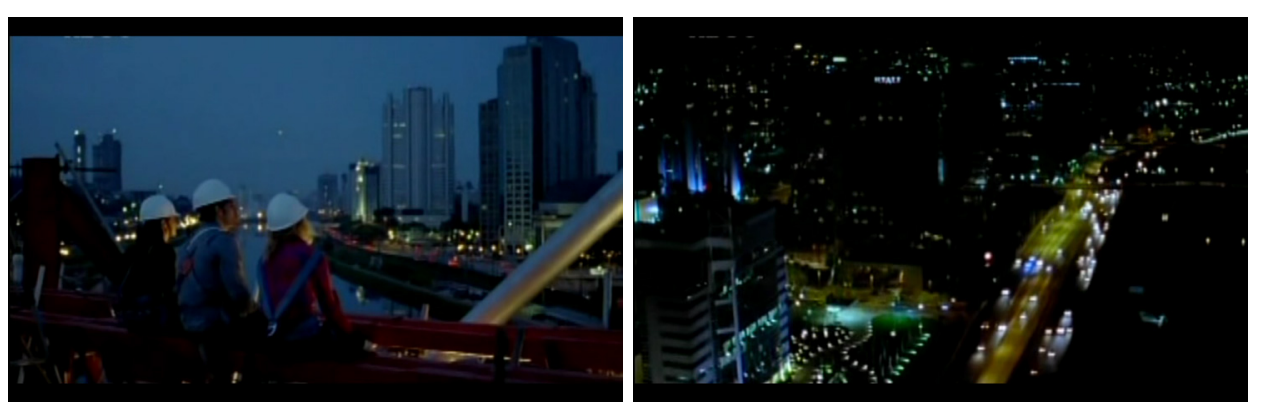

Figuras 6-7: Vista da ponte estaiada

Nota: Alice, $H B O, 2008$

\section{A Cidade Real e o Cinema Paulistano}

Num texto sobre a produção cinematográfica paulistana da primeira década dos anos 2000, Ilana Feldman destaca traços semelhantes aos que identificamos em Alice. Ela nota que, enquanto o cinema produzido no Rio de Janeiro é mais atento à violência social e urbana e aos conflitos de classe, o cinema paulista tem como pauta o "indivíduo em tensão com uma situação que não consegue ordenar, controlar ou, simplesmente, compreender" (Feldman, 2008). Assim, a fim de explorar a proximidade entre a série e o cinema paulistano, será útil percorrer alguns exemplos entre filmes já mencionados.

Em Os 12 Trabalhos, a história do jovem que busca, trabalhando como motoboy, se recuperar de um período na prisão é narrada em planos ágeis, com a câmera acoplada à moto, levando o espectador a enfrentar, junto ao personagem, os riscos do trânsito da cidade. Já em Não por Acaso, a urgência das entregas de moto cede lugar ao cálculo: a cidade real serve de matéria-prima para a construção de uma cidade esquemática e fria aos moldes do protagonista, um operador de tráfego obcecado por controlar tudo a seu redor - o que rende imagens estilizadas em tomadas aéreas fluidas e geométricas. Em $A$ Via láctea, filme construído predominantemente por imagens do protagonista em seu carro, a fragmentação da geografia urbana materializa o delírio de seus últimos instantes de vida (vítima de um acidente de trânsito), com a paisagem manifestando a luta travada contra uma desilusão amorosa. Último exemplo: em Linha de Passe, quatro irmãos têm suas vontades (encontrar o pai na figura de um motorista de ônibus; tornar-se jogador de futebol; seguir os preceitos de uma fé religiosa; e quitar as dívidas da família) ao mesmo tempo alimentadas e negadas em meio à precariedade da periferia de São Paulo - cidade que traz ao cinema de Walter Salles, segundo Felipe Bragança, "alguma coisa de caótico que lhe ajuda a ser menos totalizante e alguma coisa de frio, que lhe ajuda a ser menos "humanista'” (Valente, 2008).

A análise mais detida dessas produções, bem como a discussão sobre as relações entre os formatos seriado (de Alice) e longa-metragem (dos filmes mencionados), está além do que nos propomos a realizar aqui. Cabe ressaltar, no entanto, que a série, tanto quanto os filmes, investe em representações da cidade que recorrem a certo realismo (assentado sobretudo em locações facilmente identificáveis) para 
${ }^{8}$ Valemo-nos aqui da distinção proposta por Ismail Xavier, que entende a "transparência" como um polo cinematográfico pautado por estratégias naturalistas e ilusionistas, dentre as quais destaca-se a continuidade narrativa, aos moldes do cinema clássico de Hollywood, e a "opacidade" como um polo que, aos moldes do cinema moderno europeu, chamaria "a atenção do espectador para o filme enquanto objeto, procurando criar a consciência de que se trata de uma narração" (Xavier, 2005, p. 141). aguçar o drama dos personagens. Da cidade real, pode-se reconhecer lugares como a Avenida Paulista, a Praça Roosevelt, o Mercadão, a Galeria do Rock, o Parque do Ibirapuera. A presença da cidade real nessas produções é tal que, por vezes, elas conversam entre si: o episódio 11 ("Mil Quilômetros por Hora"), por exemplo, faz referência aos anúncios de lingerie que outrora povoavam os arredores do Minhocão, como visto em Terra estrangeira - filme que traz o elevado no centro da cidade ostentando um enorme outdoor das calcinhas Hope. A ambientação sonora da série traz ruídos das ruas mesmo em cenas internas, e as imagens com frequência buscam exprimir dinamismo por meio de mascaramentos e reflexos - aspectos também presentes nos filmes e que sugerem um equilíbrio entre filmar a cidade real e explorar a subjetividade de personagens em conflito com ela.

No entanto, apesar das filmagens em locação e do apreço temático a essa condição de estar na/atravessar a cidade, essa recente produção paulistana guarda distâncias dos pressupostos realistas do cinema apontados por André Bazin em sua leitura seminal do cinema neorrealista italiano dos anos 1950 (Bazin, 1991). Por consequência, essa produção paulistana diverge, em vários aspectos, da tendência de "retorno ao real" do cinema contemporâneo - tendência que tem sido associada à obra de realizadores como Jia Zhangke, Tsai Ming-liang, Apichatpong Weerasethakul e Gus Van Sant, dentre outros. Enquanto esses realizadores parecem buscar atenuar os efeitos imersivos/ilusionistas da narrativa clássica, operando num regime mais de opacidade que de transparência narrativa ${ }^{8}$, e retomam algumas das estratégiaschave da estética realista baziniana, a produção paulistana recente se revela mais afeita a manipulações do espaço real do que propriamente à sua preservação.

À provável exceção de $A$ Via Láctea, que apresenta uma estrutura narrativa mais fragmentária, todas as obras referidas empregam uma estrutura bastante convencional, transparente, deixando claras as motivações dramáticas dos personagens e amarrando os acontecimentos da trama em relações facilmente compreensíveis de causa e efeito. Vale notar também que Alice e Linha de Passe, de modo ainda mais pronunciado que as demais produções, recorrem com frequência a planos fechados para construir "retratos" dos protagonistas. Esses "retratos", graças à opção dos realizadores por uma fotografia com baixa profundidade de campo, trazem a cidade bastante desfocada ao fundo - estratégia que talvez favoreça a identificação afetiva com os personagens, aproximando o espectador de seus rostos, mas que, por outro lado, nos aliena do espaço real.

A produção paulistana referida aqui também não compartilha daquele que é o recurso estilístico mais caro às produções contemporâneas investidas no "retorno ao real": o plano longo (Mello \& Nagib, 2009, p. XV). A renovação da aposta baziniana na longa duração de uma imagem sem cortes, fazendo coincidir o tempo real e o tempo do filme (fazendo o espectador experimentar, no filme, a passagem do tempo real), é marca distintiva de um cinema contemporâneo que busca preservar e priorizar a realidade em detrimento do artifício ilusionista, ou melhor, de um cinema que condiciona o artifício ilusionista à potencialização dos efeitos de realidade no filme. $\mathrm{O}$ "uso hiperbólico do plano longo" é, pois, um traço definidor da "tendência realista contemporânea" (Luca, 2011, p. 192). Por esse motivo, a nosso ver, o viés realista da produção paulistana recente parece encontrar seu limite na consideração (talvez irrefletida, mas mais provavelmente desejada e planejada pelos produtores e realizadores) das confortáveis convenções de uma narrativa mais transparente, pouco disposta a renunciar às qualidades imersivas da ficção e a questionar o pacto identificatório que tende a se estabelecer entre personagens e espectadores. Colocado de outro modo, produções como Alice apenas engajam seu espectador no espaço urbano sob a condição de que esse espectador se sujeite a experimentá-lo exclusivamente através da personagem, aderindo (de um modo que nos parece mais passivo do que crítico) a seu ponto de vista, seus valores, seus desejos. Nesse passeio por São Paulo, por assim dizer, não nos é permitido afastar-nos da guia.

\section{A Travessia do Deserto}

A colocação do espaço como refúgio da memória e agente de sua deflagração, já desenvolvida nos episódios que tratam da festa no galpão da Barra Funda, é retomada 
em "À Flor da Pele", último episódio de Alice. Nele, a protagonista descobre que sua mãe, morta quando ela era pequena, não foi vítima de um problema cardíaco, como ela até então acreditava, e sim de um acidente de carro no deserto do Jalapão, no interior do Tocantins. De fato, a morte sequer foi comprovada: a mãe parece ter desaparecido no deserto, abandonando o carro nas dunas. A descoberta reconfigura a estrutura familiar de Alice. Na busca por assimilar essa nova versão de sua própria história, ela parte para o deserto (Figuras 8-9): assim como havia sido necessário reativar o galpão da Barra Funda para ressignificar a figura paterna, ela explora a aridez das dunas para recuperar o passado da mãe.
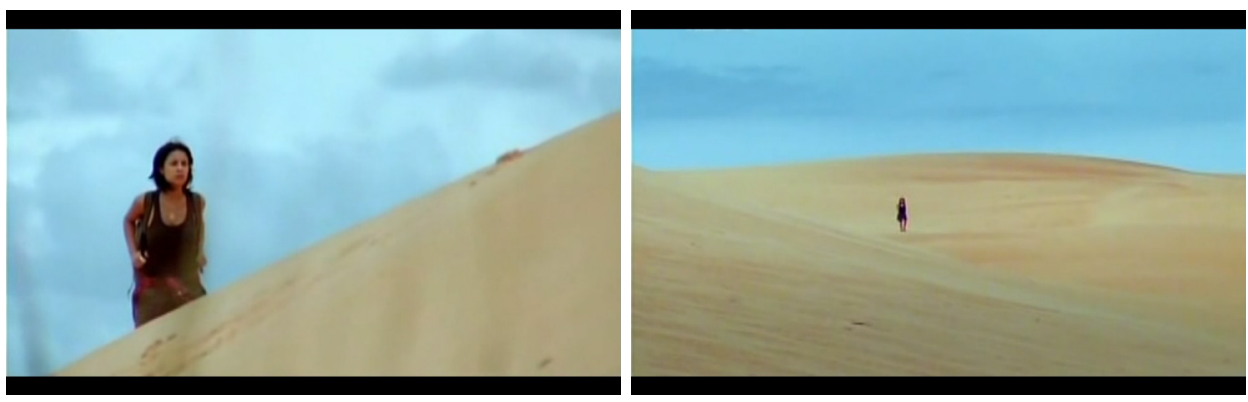

Figuras 8-9: O deserto do Jalapão

Nota: Alice, HBO, 2008.

Embora o vazio e o silêncio do deserto pareçam opostos ao princípio do "fluxo" que governa a metrópole, a travessia das dunas pode ser abordada em termos semelhantes àqueles da desorientação inicial de Alice em São Paulo. Tanto quanto a metrópole contemporânea (e não apenas para o inexperiente recém-chegado), o deserto se dá como espaço imensurável e inóspito. Ao descrever algumas de suas passagens pelo Saara, o explorador Michael Asher explica que, sem nenhum signo estável capaz de organizar visivelmente o espaço, as distâncias se dissolvem:

Fiquei observando Marinetta se afastar correndo de nossa caravana... ela ziguezagueava pela areia... quando tentei fazer o mesmo, sem nada para fixar o olhar, percebi que era impossível correr em linha reta. Qualquer ondulação ou sombra na superfície criava uma impressão de relevo. Ao nos aproximar do que parecia ser uma massa de dunas, descobríamos que ela se dissolvia em pequeninas ondas de areia. (Michael Asher, 1988, citado por Sobchack, 2004, p. 19)

Após enfrentar o deserto, Alice retorna a uma São Paulo que já não Ihe é mais hostil. Durante os créditos finais do último episódio, vemos que ela aprende a dirigir um carro - o que nos faz pensar no controle do trânsito em Não por Acaso, nos mapas do metrô de Jogo Subterrâneo e nas motos de Os 12 Trabalhos, no ônibus de $A$ Casa de Alice, nos muitos ônibus onde o caçula da família passeia à procura do pai em Linha de Passe e na jornada de carro do protagonista de A Via Láctea. $O$ domínio do transporte e de seus meios, tanto em Alice como nesses filmes, contrasta com o dinamismo, o movimento e a velocidade que determinam as representações da metrópole.

A narrativa da série opera, de certo modo, uma aceleração: antes de chegar à velocidade do carro no episódio final, episódios anteriores, especialmente no início da temporada, trazem montagens com imagens estáticas, fotográficas. Além das já mencionadas fotografias de Palmas e da família de Alice logo no início da série, destaca-se, também no primeiro episódio, a cena em que ela vê (e nós vemos com ela, congeladas na tela) as fotos do DJ que a leva para casa após a festa. Numa cena do episódio seguinte ("O Tesouro de Alice"), a tela é ocupada pelas fotos que registram seu primeiro encontro com a meiairmã. E o quarto episódio ("No Jardim das Flores Perdidas") traz fotos do aniversário de Alice no monitor de um computador. Essa recorrência de imagens fotográficas em episódios iniciais não deixa de exprimir um desejo de desaceleração, de pausa, de fixar o momento diante do fluxo intenso de novas experiências. Esse recurso é descartado à medida que a personagem se acostuma, se adapta, aceitando e se lançando no "fluxo" de São Paulo. Assim, sua imagem ao volante de um carro representa de modo inequívoco a conclusão de seu arco dramático: assumir a direção de um carro é, para Alice, uma cristalização de seu domínio da cidade. 


\section{Recomeçar de Novo}

Dois anos após o último episódio, a HBO exibiu dois telefilmes que retomavam o universo de Alice. Mais do que um encerramento, no entanto, os telefilmes operam um recomeço. "Recomeçar, recomeçar, mil vezes recomeçar, recomeçar de novo, recomeçar sempre, recomeçar": o lamento do protagonista de São Paulo S/A (filme que a personagem havia assistido enquanto trabalhava na produção da Mostra de Cinema de São Paulo, num longínquo segundo episódio) serve como prenúncio de mudanças. Se, para Alice, "a adequação é a morte" (Feldman \& Eduardo, 2007, p. 14), não basta dominar a cidade. É preciso desestruturar a personagem, fazê-la questionar uma vez mais seu lugar e se relançar no "fluxo". Afinal, como afirma Bauman sobre as identidades "pós-modernas", o problema não é construir e manter uma identidade, mas evitar toda e qualquer forma de fixação e manter em aberto suas possibilidades (Bauman, 1996, p. 18).

O primeiro telefilme (O Primeiro Dia do Resto da Minha Vida) encontra Alice em um relacionamento amoroso estável, dirigindo com naturalidade pela cidade (ainda que com a ajuda de um aparelho de GPS) à procura de um apartamento para comprar. Seus planos, como os que ela tinha em Palmas antes de se mudar para São Paulo, serão rapidamente desfeitos: ela desiste de visitar novos imóveis e rompe com o namorado. No segundo telefilme ( $A$ Última Noite), irritada com o desfazer de seus projetos, Alice bate o carro. A batida de carro surge, tal como no Contra a Parede analisado por Cecília Mello (2013), como signo maior de uma brutal imobilidade. Após o acidente, ela perambula sozinha pelas ruas do centro. Nessa cena, uma vez mais (uma última vez), a personagem e a metrópole se encontram entrelaçadas e em construção. A locução em voz over explicita sua inquietação:

A gente sente a hora exata em que a gota d'água entorna o copo. Estou sentindo um vazio, como se de uma hora pra outra alguém tivesse roubado o chão debaixo dos meus pés. Vontade de andar, andar, andar. Sem chegar a lugar algum.

Caminhando à noite por essas ruas desertas, Alice se depara com um telefone público que parece chamar por ela. $O$ espectador pode supor que sua resposta a essa ligação a levará por muitas outras ruas, outros bares e outras festas, sem seus amigos habituais e sem planos para o futuro. "A última noite" é, pois, uma abertura para novas experiências da cidade e véspera de uma nova Alice.

Buscamos, neste artigo, refletir sobre o modo como a série Alice se apropria da cidade de São Paulo para construir uma outra São Paulo - uma cidade imaginária que é espelho da protagonista. Contando com uma forte identificação entre a personagem e o espectador, a série constrói para ele uma metrópole contemporânea ideal a partir dos fragmentos filmados da cidade real. Após considerações iniciais mais amplas acerca da noção mesma de uma "metrópole contemporânea" e do imaginário tradicionalmente mobilizado pela cidade de São Paulo, observamos como a cidade se articula narrativa e esteticamente na série, se colocando plenamente à serviço das demandas afetivas de sua protagonista, ao mesmo tempo que tem suas representações conformadas por elas. Nesse processo, que buscou também colocar a série em diálogo com produções que lhe são conterrâneas e contemporâneas e com uma tendência cinematográfica internacional de "retorno ao real", observamos que Alice mobiliza criticamente princípios usualmente atribuídos à metrópole contemporânea: aos termos habituais do "fluxo" (transparência, luz, circulação), a série incorpora sensualidade, sedução, prazer. A metrópole emerge não apenas como um espaço de densidades e intensidades, um mundo onde tudo parece ser possível, mas também como uma experiência afetiva implicada no corpo, um catalisador e amplificador de medos e desejos. A São Paulo de Alice é um espaço de desorientação e de reelaboração do passado, da memória, da própria identidade individual, sob o modo cíclico do recomeço. Não é, pois, a cidade do controle e do progresso, sempre para frente, como tantas vezes se diz. Nela, é impossível correr em linha reta. 


\section{Referências}

AUGÉ, M. (2010). Por uma antropologia da mobilidade. Edufal; Unesp.

BAUMAN, Z. (1996). From pilgrim to tourist - Or a short history of identity. In S. Hall, \& P. Du Gay (Orgs.), Questions of cultural identity (pp. 18-36). Sage.

BAUMAN, Z. (2001). Modernidade líquida. Jorge Zahar.

BAZIN, A. (1991). O cinema: Ensaios. Brasiliense.

BENJAMIN, W. (1991). Paris, capital do século XIX. In F. Kothe (Org.), Walter Benjamin (pp. 30-43). Ática.

BRUNO, G. (2007). Atlas of emotion: Journeys in art, architecture and film. Verso.

CALVINO, I. (1990). As cidades invisíveis. Companhia das Letras.

CARROLL, L. (2010). Aventuras de Alice no país das maravilhas e Através do espelho e o que Alice encontrou por lá. Jorge Zahar.

FELDMAN, I. (2008). Do trânsito ao transe-to: Descontrole e desorientação em Não por Acaso, A Via Láctea e A Casa de Alice. Revista Cinética. http://www.revistacinetica. com.br/transitoilana.htm.

FELDMAN, I., \& EDUARDO, C. (2007). A política do corpo e o corpo político: O cinema de Karim Aïnouz. Revista Cinética. http://www.revistacinetica.com.br/ cep/karim_ainouz.pdf

FOLHA DE S.PAULO. (2015, 1 de julho). Criadora do 'piso paulista' diz que nunca recebeu 1 centavo pelo desenho. Folha de S.Paulo. https://www.youtube.com/ watch?v=BLGKXZUrfnQ

LEONARDE, A. (2014). A identidade histórico-cultural de São Paulo por meio de sua narrativa identitária: A cidade do trabalho e do entretenimento. Licere, 17(4), 198-235. https://doi.org/10.35699/1981-3171.2014.1053

LUCA, T. (2011). Realism of the senses: A tendency in contemporary world cinema. In R. Dudrah, L. Nagib, \& C. Perriam (Orgs.), Theorizing world cinema (pp. 183-205). Tauris.

MACHADO JR., R. (1989). São Paulo em movimento: A representação cinematográfica da metrópole nos anos 20 (Dissertação de mestrado). Universidade de São Paulo.

MACHADO JR., R. (2007). Imagens brasileiras da metrópole: A presença da cidade de São Paulo na história do cinema (Memorial de livre docência). Universidade de São Paulo.

MACHADO JR., R. (2008). Plano em grande angular de uma São Paulo fugidia. Comunicação e Informação, 11(2), 192-196. https://doi.org/10.5216/c\&i.v11i2.7486

MASCARENHAS, A. (2014). A televisão transmídia de Alice: Reconfiguração narrativa na televisão fechada brasileira. In A. Mascarenhas, E. Pinheiro, \& O. Tavares (Orgs.), Culturas midiáticas e audiovisuais: Estudos (pp. 9-37). Ideia.

MASSEY, D. (2008). Pelo espaço. Bertrand Brasil.

MELLO, M. C. (2007, 22 de agosto). O tesão alimenta a alma, diz Karim Aïnouz, diretor da série "Alice", da HBO. UOL Entretenimento. http://televisao.uol.com.br/ ultimas-noticias/2007/08/22/ult4244u299.jhtm

MELLO, C. (2013). Um conto de duas cidades. In A. Brandão, A. Corseuil, \& R. Lira (Orgs.), Cinema, globalização e transculturalidade (pp. 119-136). Nova Letra. 
MELLO, C., \& NAGIB, L. (Orgs.). (2009). Realism and the audiovisual media. Palgrave Macmillan.

MERLEAU-PONTY, M. (2003). O visível e o invisível. Perspectiva.

MONTERO, P. (2008). Passagens na metrópole paulistana do século XXI. Novos estudos Cebrap, (82), pp. 191-199. https://doi.org/10.1590/S0101-33002008000300011

PUCCI, R. (2008). Cinema brasileiro pós-moderno: o neon-realismo. Sulina.

SOBCHACK, V. (2004). Breadcrumbs in the forest: Three meditations on being lost in space. In V. Sobchack, Carnal thoughts: Embodiment and moving image culture (pp. 13-35). University of California Press.

VALENTE, E. (Ed.). (2008). Linha de passe, de Daniela Thomas e Walter Salles (Brasil, 2008). Revista Cinética. http://www.revistacinetica.com.br/linhadebate.htm.

XAVIER, I. (2005). O discurso cinematográfico: A opacidade e a transparência. Paz e Terra.

XAVIER, I. (2006). São Paulo no cinema: Da coesão da cidade-máquina à corrosão da cidade arquipélago. Sinopse, 8(11), 18-25. 